\title{
Response of Peanut, Pepper, Tobacco, and Tomato Cultivars to Two Biologically Distinct Isolates of Tomato spotted wilt virus
}

\author{
B. Mandal, Department of Plant Pathology, University of Georgia, Coastal Plain Experiment Station, Tifton 31793; \\ H. R. Pappu, Department of Plant Pathology, P.O. Box 646430, Washington State University, Pullman 99164-6430; \\ and A. S. Csinos and A. K. Culbreath, Department of Plant Pathology, University of Georgia, Coastal Plain Ex- \\ periment Station, Tifton 31793
}

\begin{abstract}
Mandal, B., Pappu, H. R., Csinos, A. S., and Culbreath, A. K. 2006. Response of peanut, pepper, tobacco, and tomato cultivars to two biologically distinct isolates of Tomato spotted wilt virus. Plant Dis. 90:1150-1155.

Spotted wilt disease, caused by Tomato spotted wilt virus (TSWV), is an economically important disease in peanut, pepper, tobacco, and tomato in the southeastern United States. However, very little is known about the biological variability existent in the virus population. Fourteen isolates of TSWV collected in Georgia were evaluated for symptom severity. The majority of the isolates produced severe systemic necrosis. One mild (GATb-1) and one severe (GAL) isolate were further examined because of the distinct differences in their virulence and symptomatology on tobacco. GATb-1 caused a few chlorotic spots and mild systemic symptoms, whereas GAL produced a large number of local lesions and severe systemic necrosis. Distinct differences in the response of selected commercial cultivars of peanut, tobacco, and tomato to GATb- 1 and GAL infection were observed. GAL was lethal to a widely grown tobacco cultivar, K326. Georgia Green, a field resistant peanut cultivar, and C11-2-39, a breeding line with the highest level of known resistance to TSWV, were more susceptible to GAL than to GATb-1. BHN 444, a newly released TSWV-resistant tomato cultivar, showed a resistant reaction, whereas Stiletto, a newly released TSWV-resistant pepper cultivar, was susceptible to both GATb-1 and GAL isolates. Information on the biological diversity of TSWV may be useful in developing more durable TSWV-resistant crops.
\end{abstract}

Additional keywords: Bunyaviridae, thrips, Tospovirus

Tomato spotted wilt virus (TSWV), genus Tospovirus and family Bunyaviridae $(25,26)$, is one of the most widely occurring and economically important plant viruses (38). TSWV has a wide host range and is transmitted by several species of thrips $(42,43)$. The TSWV genome consists of three segments of RNA: Large (L), Medium (M), and Small (S) (1). The tripartite genome organization of TSWV allows exchange of genetic information through genome reassortment $(16,18$, $34,35)$. In nature, TSWV exists as a complex of strains $(3,4,9,15,17,28)$. The diversity in virus populations helps TSWV rapidly adapt to a resistant host. Breakdown of virus resistance in commercial crops

Corresponding author: H. R. Pappu

E-mail: hrp@wsu.edu

Current address of B. Mandal: Plant Virology Unit, Division of Plant Pathology, Indian Agricultural Research Institute, New Delhi 110012, India.

* The $\boldsymbol{e}$-Xtra logo stands for "electronic extra" and indicates that Figures 1 and 2 will appear in color in the online edition.

Accepted for publication 19 April 2006.

DOI: $10.1094 /$ PD-90-1150

(C) 2006 The American Phytopathological Society like tomato and pepper has been reported $(10,17,18,20,24)$.

TSWV is a production constraint to peanut, pepper, tobacco, and tomato in Georgia (29). Annual total losses due to TSWV in these crops in Georgia are estimated at several million dollars (44). Management of TSWV is largely dependent upon the use of resistant cultivars in combination with certain cultural practices (8,11-14,23,32,36,37). Since TSWV has been shown to overcome resistance in commercial crops $(10,17,20,24)$, knowledge on the prevalence of TSWV isolates in a particular geographic location is important for breeding resistant cultivars that are durable. Sequence diversity of TSWV isolates occurring in Georgia has been studied previously $(5,19,31,33)$. The evolutionary biology of TSWV based on sequence analysis has been the subject of further studies $(27,41)$. However, little or no information is available on the prevalence of strains that differ in pathogenicity.

The objective of the present study was to determine the biological diversity of TSWV isolates existing in southern Georgia. Several isolates of TSWV from Tift and Colquitt counties were compared by mechanical inoculation on tobacco cultivar K326 under identical environmental conditions. Two isolates with differential sever- ity of disease expression were selected and further characterized. Reactions of commercial cultivars of peanut, pepper, tobacco, and tomato to these two isolates were evaluated.

\section{MATERIALS AND METHODS}

Collection and transmission of TSWV isolates. Fourteen isolates of TSWV were collected from tobacco (Nicotiana tabacum) grown on the Bowen Farm and the Black Shank Farm of the Coastal Plain Experiment Station, University of Georgia, Tifton, and one isolate from lettuce from Colquitt County, GA. TSWV infection in these source plants was confirmed by enzyme linked-immunosorbent assay (ELISA) using a commercial kit (Agdia Inc., Elkhart, IN). ELISAs were also conducted to ensure absence of a mixed infection with Tobacco mosaic virus, Cucumber mosaic virus, or Potato virus $Y$ in the samples. One hundred milligrams of each leaf sample containing a single lesion or a portion of systemic necrosis was ground in $1 \mathrm{ml}$ of $0.1 \mathrm{M}$ potassium phosphate buffer, $\mathrm{pH}$ 7.0, containing $0.2 \% \mathrm{Na}_{2} \mathrm{SO}_{3}$ and $0.01 \mathrm{M}$ mercaptoethanol. To the sap, Celite 545 and Carborundum 320 grit (Fisher Scientific, Fair Lawn, NJ) were added. All the isolates were separately inoculated onto two leaves of 1-month-old individual tobacco plants cv. K326. Inoculated plants were kept in a growth chamber at 25 to $30^{\circ} \mathrm{C}, 60$ to $90 \%$ relative humidity, and $12 \mathrm{~h}$ each light (light intensity 15 to $20 \mathrm{klx}$ ) and dark period daily.

Selection of mild and aggressive isolates. Three lesions from each plant inoculated with each isolate of TSWV were initially tested at 5 days postinoculation (DPI) separately in a 10-fold dilution series by ELISA using a monoclonal antibody specific to TSWV nonstructural protein, NSs (2). For asymptomatic plants, an equal amount of leaf disks was tested by ELISA. Inoculated plants were allowed to grow for a month to allow for the development of systemic symptoms. A month after inoculation, two isolates were selected for further study: a tobacco isolate (GATb-1) that induced mild symptoms and a lettuce isolate (GAL) that induced severe symptoms. These isolates were further propagated on tobacco. These two isolates were successively transferred three times from single lesions to K326 under the 
same environmental conditions. Then, from the third single-lesion transfer, the isolates were propagated and maintained in tomato (Lycopersicon esculentum) cv. Sunny.

Comparison of aggressiveness of GATb-1 and GAL isolates. A $10^{-1}$ or $10^{-2}$ dilution of symptomatic tomato leaves for each isolate was used separately to inoculate a single excised leaf $(11 \mathrm{~cm}$ long and 7 $\mathrm{cm}$ wide) of $N$. tabacum cv. Xanthi grown in the growth chamber. Inoculation to a single leaf was considered as a replication, and for each dilution three replications were included. Each inoculated leaf was kept floating on autoclaved distilled water in a separate plastic container. Inoculated leaves in the plastic container were kept completely randomized in the growth chamber. Expression of symptoms was monitored visually on a daily basis. Six lesions (from both dilutions) for each isolate were tested separately by ELISA to confirm the presence of TSWV.
Cultivars. Three cultigens of peanut (Arachis hypogaea) were used. Georgia Runner is considered susceptible to TSWV, whereas Georgia Green and C112-39 have field resistance to TSWV. BHN 444 (BHN Research, Bonita Springs, FL) and Sunny are TSWV-resistant and -susceptible tomato cultivars, respectively. Pepper (Capsicum annuum) cv. Stiletto (Novartis/Rogers Brand Seed) and Yellow Wonder were used. Stiletto was released as a TSWV-resistant cultivar.

Evaluation of susceptibility of tobacco, peanut, tomato, and pepper cultivars to GAL and GATb-1 isolates. Inocula for both isolates were prepared from infected tomato as described above. Two leaves of tobacco cv. K326 seedlings ( 25 days after planting) were inoculated with either isolate at $10^{-1}$ and $10^{-2}$ dilutions.

Six- to-seven day-old peanut seedlings were inoculated separately with the two isolates. One-month-old tomatoes and peppers were inoculated with the two iso-

Table 1. Response of tobacco cv. Xanthi to infection by GATb-1 and GAL isolates of Tomato spotted wilt virus

\begin{tabular}{|c|c|c|c|c|c|}
\hline \multirow[b]{2}{*}{ Isolate } & \multirow[b]{2}{*}{$\begin{array}{l}\text { Dilution } \\
\text { of sap }\end{array}$} & \multirow[b]{2}{*}{ Replication $^{x}$} & \multicolumn{3}{|c|}{$\begin{array}{c}\text { Number of lesions developed } \\
\text { on each laminaw }\end{array}$} \\
\hline & & & $3 \mathrm{DPI}^{\mathrm{y}}$ & 5 DPI & $\begin{array}{l}\text { Meanz }^{z} \\
\text { at } 5 \text { DPI }\end{array}$ \\
\hline \multirow[t]{6}{*}{ GATb-1 } & $10^{-1}$ & I & 0 & 9 & \\
\hline & & II & 1 & 3 & $6.33 \mathrm{~b}, \mathrm{~m}$ \\
\hline & & III & 5 & 7 & \\
\hline & $10^{-2}$ & I & 0 & 0 & \\
\hline & & & 0 & 0 & $0.66 \mathrm{a}, \mathrm{m}$ \\
\hline & & III & 0 & 2 & \\
\hline \multirow[t]{6}{*}{ GAL } & $10^{-1}$ & I & 60 & 78 & \\
\hline & & II & 80 & 120 & $100 \mathrm{~b}, \mathrm{n}$ \\
\hline & & III & 93 & 102 & \\
\hline & $10^{-2}$ & I & 0 & 13 & \\
\hline & & II & 0 & 29 & $21.3 \mathrm{a}, \mathrm{n}$ \\
\hline & & III & 4 & 22 & \\
\hline
\end{tabular}

${ }^{\mathrm{w}}$ GATb-1 and GAL caused chlorotic lesions and necrotic lesions, respectively.

${ }^{\mathrm{x}}$ Inoculation of single excised leaf $11 \mathrm{~cm}$ long and $7 \mathrm{~cm}$ wide was considered replication.

y Days postinoculation.

${ }^{\mathrm{z}} \mathrm{a}, \mathrm{b}$ or $\mathrm{m}, \mathrm{n}$ denote significant difference between pairs of means within a dilution level or isolate, respectively, at $P=0.05$. LSD between isolates within dilution level $=51.5, \mathrm{df}=2$; LSD between dilutions within an isolate $=15.2, \mathrm{df}=4$. lates. For peanut, tomato, and pepper, inocula were prepared from tomato infected with the two isolates at the rate of $1: 6$ (wt/vol) tissue to buffer ratio. Mechanical inoculations were done as previously described (21).

Detection of infection and statistical analysis. Inoculated plants were monitored visually, and both local and systemic infections were confirmed by ELISA using a commercially available kit for TSWV detection (Agdia). Data were analyzed by Proc MIXED (SAS, Version 8, 2000, SAS Institute Inc., Cary, NC). The statistical model for analysis of response of tobacco (N. tabacum cv. Xanthi and N. tabacum cv. K326, Tables 1 and 2) was split plot with three replications having main plot as isolate, subplot as dilution. The model for analysis of tomato cultivars (Table 3 ) was a split plot with three replications, where cultivar and isolate were the main plot and local and systemic symptoms were the subplot. For the analysis of response of peanut (Table 4) and pepper (Table 5), the model was a randomized complete block with three replications and a factorial with three cultigens for peanut and two cultigens for pepper by two isolates each.

\section{RESULTS}

Reactions of the field isolates. In the field, TSWV isolates exhibited a wide range of symptoms (Fig. 1). Upon mechanical inoculation of tobacco K326, test plants produced local lesions on the inoculated leaves 3 to 5 DPI. The number of lesions that developed after inoculation varied from 0 to 186 per plant. There were differences in the type of local lesions produced. Some isolates, including GAL, produced necrotic rings with green tissues inside, or lesions with a blighted center and a brown margin around. At 7 to 30 DPI, the majority of the isolates produced severe systemic necrosis. Some isolates did not induce a large number of local lesions but produced systemic necrotic symptoms. Only one isolate, GATb-1, did

Table 2. Response of tobacco cv. K326 to infection by GATb-1 and GAL isolates of Tomato spotted wilt virus

\begin{tabular}{|c|c|c|c|c|c|c|c|}
\hline \multirow[b]{3}{*}{ Isolate $^{y}$} & \multirow[b]{3}{*}{ Replication } & \multicolumn{6}{|c|}{ Dilution of sap ${ }^{x}$} \\
\hline & & \multicolumn{3}{|c|}{$10^{-1}$} & \multicolumn{3}{|c|}{$10^{-2}$} \\
\hline & & $\begin{array}{l}\text { No. plants } \\
\text { infected/ } \\
\text { inoculated }\end{array}$ & $\begin{array}{l}\text { Mean no. } \\
\text { of lesions } \\
\text { per plant }\end{array}$ & $\begin{array}{c}\text { Mean } \\
\text { lesions } \\
\text { in four trials }\end{array}$ & $\begin{array}{l}\text { No. plants } \\
\text { infected/ } \\
\text { inoculated }\end{array}$ & $\begin{array}{l}\text { Mean no. } \\
\text { of lesions } \\
\text { per plant }\end{array}$ & $\begin{array}{c}\text { Meanz }^{z} \\
\text { lesions } \\
\text { in four trials }\end{array}$ \\
\hline \multirow[t]{4}{*}{ GATb-1 } & I & $5 / 5$ & 5.8 & \multirow{4}{*}{$5.65 \mathrm{a}, \mathrm{n}$} & $3 / 5$ & 1.0 & \multirow{4}{*}{$1.07 \mathrm{a}, \mathrm{n}$} \\
\hline & II & $5 / 5$ & 4.0 & & $2 / 5$ & 1.2 & \\
\hline & III & $9 / 9$ & 6.6 & & $3 / 9$ & 0.6 & \\
\hline & IV & $8 / 9$ & 6.2 & & $3 / 9$ & 1.5 & \\
\hline \multirow{4}{*}{ GAL } & I & $5 / 5$ & 43.2 & \multirow{4}{*}{$36.95 \mathrm{~b}, \mathrm{n}$} & $5 / 5$ & 12.6 & \multirow{4}{*}{$10.27 \mathrm{~b}, \mathrm{~m}$} \\
\hline & II & $5 / 5$ & 34.0 & & $5 / 5$ & 12.4 & \\
\hline & III & $9 / 9$ & 40.0 & & $8 / 9$ & 8.7 & \\
\hline & IV & $9 / 9$ & 30.6 & & $8 / 9$ & 7.4 & \\
\hline
\end{tabular}

${ }^{\mathrm{x}}$ Two leaves for each plant (25 days after planting) were inoculated. Lesions were counted 5 days postinoculation.

${ }^{y}$ GATb-1 and GAL caused chlorotic lesions and necrotic lesions, respectively.

${ }^{\mathrm{z}} \mathrm{a}, \mathrm{b}$ or $\mathrm{m}, \mathrm{n}$ denote significant difference between pairs of means within dilution of sap or isolate, respectively, at $P=0.05$. LSD between isolates within a dilution level $=8.4, \mathrm{df}=3$; $\mathrm{LSD}$ between dilutions within an isolate $=4.5, \mathrm{df}=6$. The model was split plot with three replications, main plot was isolate, subplot was dilution. 
not produce severe systemic necrosis. However, it produced mottling, green circular lines, or chlorotic concentric rings and minute necrotic dots, which were scattered over the inoculated leaves. Based on distinct differences in the severity of systemic symptoms, GATb-1 and GAL were selected for successive passaging of single lesions in tobacco. GATb-1 produced a few chlorotic spots (Fig. 2), whereas GAL produced large numbers of necrotic lesions (Fig. 2) and wilting of the leaves. Following single-lesion transfers, cultures of GATb-1 and GAL were established which were used to determine the responses of cultivars of peanut, pepper, tobacco, and tomato.

Comparison of severity of GATb-1 and GAL isolates in N. tabacum cv. Xanthi. Inoculation of GATb-1 to the excised leaves of $N$. tabacum cv. Xanthi resulted in 6.33 and 0.66 chlorotic spots per leaf at $10^{-1}$ and $10^{-2}$ dilutions, respectively (Table 1 ). In comparison, GAL produced a larger number of necrotic lesions, 100 and 21.3 per leaf at $10^{-1}$ and $10^{-2}$ dilutions, respectively (Table 1). There was an interaction between isolates and dilution of sap, and they were significantly different at $P=$ 0.05 .

Susceptibility of different crops to GATb-1 and GAL isolates. In the four inoculation trials using a commercial tobacco cultivar, K326, isolate GATb-1 produced a mean of 4 to 6.6 and 0.6 to 1.5 chlorotic spots at $5 \mathrm{DPI}$ at $10^{-1}$ and $10^{-2}$ dilutions, respectively, on the inoculated leaves (Table 2). Leaves inoculated with isolate GATb-1 did not wilt. At 10 to 15 DPI, plants showed systemic symptoms such as mottling, wavy circular green lines, chlorotic rings, and concentric rings. The GAL isolate produced lesions as early as 3 DPI, and by 5 DPI a large number of lesions developed on the inoculated leaves. In the four inoculation trials, GAL produced 30.6 to 43.2 and 7.4 to 12.6 necrotic lesions per plant at the $10^{-1}$ and $10^{-2}$ dilutions, respectively (Table 2). Inoculated leaves wilted by 5 to 6 DPI, while systemic necrosis developed on the newly expanding leaves. Plants were stunted and died by 3 to 4 weeks postinoculation. The isolates infected similar numbers of plants following inoculation with the $10^{-1}$ dilution of inoculum, but GAL produced more infected plants than GATb-1 at higher dilution (Table 2). There was a significant difference in the severity of disease caused by these two isolates as judged by the number of local lesions and chlorotic spots.

In the case of peanut, both isolates induced yellow spots, rings, or concentric rings in the newly developed leaves. There were no pronounced differences in symptomatology between the two isolates. However, inoculation of peanut cultigens Georgia Green, Georgia Runner, and C112-39 with isolate GAL resulted in a higher percentage of infected plants than inoculation with GATb-1 (Table 4). GATb-1 infec- tion resulted in a higher percentage of systemically infected plants in the case of Georgia Green and Georgia Runner (76.6 and $81.9 \%$, respectively) than in C11-2-39. There were no significant differences in the number of plants of Georgia Green and Georgia Runner infected with either isolate (Table 4). However,GATb-1 produced a significantly lower percentage $(23 \%)$ of systemically infected C11-2-39 plants (Table 4) than that caused by GAL. Of the three cultigens, only C11-2-39 showed a differential response to the two isolates.

Both GATb-1 and GAL isolates produced mosaic and stunting of plants in the tomato cultivar Sunny. One month after inoculation with GAL, many necrotic brown lesions and concentric rings developed on new leaves, while at the same time plants inoculated with GATb-1 showed chlorotic concentric rings, distortion of leaves, and minor necrosis. Both the iso-

Table 4. Response of peanut to GAL and GATb-1 isolates of Tomato spotted wilt virus

\begin{tabular}{llcccc}
\hline & & \multicolumn{3}{c}{ No. plants infected/inoculated } & \multirow{2}{*}{$\begin{array}{c}\text { Mean \% } \\
\text { infected } \\
\text { Clants }\end{array}$} \\
\cline { 3 - 4 } Cultigen & Isolate & I & II & III $^{\mathbf{y}}$ & \\
\hline C11-2-39 & GAL & $6 / 10$ & $5 / 7$ & $10 / 10$ & $78.2 \mathrm{~b}, \mathrm{n}$ \\
& GATb-1 & $2 / 9$ & $2 / 11$ & $3 / 10$ & $23.0 \mathrm{a}, \mathrm{m}$ \\
Georgia Runner & GAL & $6 / 7$ & $10 / 10$ & $9 / 10$ & $91.9 \mathrm{a}, \mathrm{n}$ \\
& GATb-1 & $8 / 10$ & $6 / 7$ & $8 / 10$ & $81.9 \mathrm{a}, \mathrm{n}$ \\
& GAL & $8 / 10$ & $10 / 10$ & $10 / 10$ & $93.3 \mathrm{a}, \mathrm{n}$ \\
& GATb-1 & $6 / 10$ & $10 / 10$ & $7 / 10$ & $76.6 \mathrm{a}, \mathrm{n}$ \\
\hline
\end{tabular}

y Three replications.

${ }^{\mathrm{z}} \mathrm{a}, \mathrm{b}$ or $\mathrm{m}, \mathrm{n}$ denote significant difference between the means of isolates or cultigens within the other factor, respectively, at $P=0.05$. LSD between isolates and cultigens within the other factor $=22.2$, $\mathrm{df}=10$.

Table 5. Response of two pepper varieties to GATb-1 and GAL isolates of Tomato spotted wilt virus

\begin{tabular}{llcccc}
\hline & & \multicolumn{3}{c}{ No. plants infected/inoculated } & \multirow{2}{*}{$\begin{array}{c}\text { Mean \% } \\
\text { Cultivars }\end{array}$} \\
\cline { 3 - 5 } infected plants
\end{tabular}

${ }^{\mathrm{z}}$ LSD between cultivars or isolates within other factor $=23.8, \mathrm{df}=6$.

Table 3. Response of two tomato cultivars to GATb-1 and GAL isolates of Tomato spotted wilt virus (TSWV)

\begin{tabular}{|c|c|c|c|c|c|c|c|c|}
\hline \multirow[b]{2}{*}{ Cultivar } & \multirow[b]{2}{*}{ Isolate } & \multicolumn{2}{|c|}{ Symptoms $^{w}$} & \multirow{2}{*}{$\begin{array}{l}\text { Site of virus } \\
\text { detection }^{\mathrm{x}}\end{array}$} & \multicolumn{3}{|c|}{ No. plants infected/inoculated } & \multirow{2}{*}{$\begin{array}{c}\text { Mean \% } \\
\text { infected plants }\end{array}$} \\
\hline & & Local & Systemic & & I & II & IIII $^{\mathbf{y}}$ & \\
\hline BHN444 & $\begin{array}{l}\text { GATb-1 } \\
\text { GAL }\end{array}$ & $\begin{array}{l}- \\
+\end{array}$ & - & $\begin{array}{l}\text { Inoculated leaf } \\
\text { New leaf } \\
\text { Inoculated leaf } \\
\text { New leaf }\end{array}$ & $\begin{array}{r}1 / 15 \\
0 / 15 \\
12 / 15 \\
2 / 15\end{array}$ & $\begin{array}{r}0 / 10 \\
0 / 10 \\
10 / 10 \\
1 / 10\end{array}$ & $\begin{array}{l}2 / 10 \\
0 / 10 \\
8 / 10 \\
1 / 10\end{array}$ & $\begin{array}{c}8.7 \mathrm{a}, \mathrm{m}, \mathrm{q} \\
0 \mathrm{a}, \mathrm{m}, \mathrm{q} \\
86.0 \mathrm{~b}, \mathrm{n}, \mathrm{r} \\
11.3 \mathrm{a}, \mathrm{m}, \mathrm{q}\end{array}$ \\
\hline Sunny & $\begin{array}{l}\text { GATb-1 } \\
\text { GAL }\end{array}$ & - & $\begin{array}{l}+ \\
+\end{array}$ & $\begin{array}{l}\text { New leaf } \\
\text { New leaf }\end{array}$ & $\begin{array}{l}12 / 15 \\
15 / 15\end{array}$ & $\begin{array}{r}8 / 10 \\
10 / 10\end{array}$ & $\begin{array}{r}10 / 10 \\
7 / 10\end{array}$ & $\begin{array}{l}86.0 \mathrm{a}, \mathrm{m}, \mathrm{r} \\
91.0 \mathrm{a}, \mathrm{m}, \mathrm{r}\end{array}$ \\
\hline
\end{tabular}

${ }^{w}$ Local and systemic symptoms indicate necrotic spots on the inoculated leaves and mosaic or necrosis on the new leaves that emerged after inoculation. $-:$ absence of symptoms, +: presence of symptoms.

${ }^{\mathrm{x}}$ TSWV was detected by enzyme-linked immunosorbent assay (ELISA) on the inoculated leaf at 10 days postinoculation (DPI) and again in the same plant at 25 DPI to confirm local and systemic infection. ELISA data of local infection of inoculated leaves on cv. Sunny were not shown, because they were the same as infection shown on new leaf.

y Three replications.

${ }^{\mathrm{z}} \mathrm{a}$, b denotes significant difference between local and systemic infection; $\mathrm{m}, \mathrm{n}$ denotes significant difference between isolates; $\mathrm{q}, \mathrm{r}$ denotes significant difference between cultivars at $P=0.05$. Values marked with the same letter are not significantly different. LSD between cultivars $(\mathrm{q}, \mathrm{r})$ or isolates $(\mathrm{m}, \mathrm{n})$ within other two factors $=17.4, \mathrm{df}=6$. LSD between local and systemic infection $(\mathrm{a}, \mathrm{b})$ within a cultivar and isolate $=16.4, \mathrm{df}=8$. 
lates produced a similarly higher percentage ( 86 and $91 \%$ by GATb-1 and GAL isolates, respectively) of systemically infected plants of cultivar Sunny (Table 3) compared with cultivar BHN 444.

Inoculation of tomato cultivar BHN 444 with GAL resulted in brown necrotic spots on the inoculated leaves at 3 to 5 DPI. At 10 DPI, lesions became larger, and yellow tissue developed around the brown spots. No systemic necrosis or stunting was observed in plants that produced localized symptoms on the inoculated leaves. ELISA, however, showed the presence of TSWV in the new leaves of $11.3 \%$ of the inoculated plants, indicating an asymptomatic but systemic infection. Inoculation of GATb-1 to BHN 444 resulted in no necrotic spots or mosaic on the inoculated leaves. No symptoms were observed on the newly developed leaves. However, $8.7 \%$ of the plants showed the presence of TSWV in the inoculated leaves, but none showed the presence of TSWV in the new leaves (Table 3).

Pepper cultivar Stiletto produced blackish brown necrotic lesions and veinal necrosis on the inoculated leaves at 5 DPI with GAL. Necrotic spots were observed in the newly developed leaves. Inoculated leaves with necrosis and newly developed leaves with even a few necrotic spots abscised prematurely. All the leaves abscised in plants showing pronounced necrosis, and the remaining green stems became severely stunted in $40 \%$ of the inoculated plants. Necrosis also was observed on the stems where all the leaves had abscised. Plants that had minor necrosis or no necrosis on the inoculated leaves grew further and produced new leaves. These plants showed systemic symptoms such as chlorotic concentric rings on the mature leaves, while younger leaves were symptomless.

Stiletto plants inoculated with the GATb-1 isolate initially produced minor necrosis on the inoculated leaves, and later the new leaves showed yellow spots, mosaic, chlorotic rings, and occasional necrotic spots. Stiletto infected with GATb-1 produced more prominent systemic mosaic symptoms than the GAL isolate, which caused more necrotic symptoms. Pepper cultivar Yellow Wonder exhibited severe systemic mosaic, ring spot, necrosis, and stunting when inoculated with either isolate. There was no significant difference in the percentage of infected Stiletto plants resulting from infection by the two isolates (Table 5).

\section{DISCUSSION}

Reactions of 14 TSWV isolates were compared following their transfer to tobacco cultivar K326. There was variation in the size, appearance, and number of local lesions on inoculated leaves among the isolates studied. Local infections leading to systemic infection that had a signifi- cant effect on plant growth and survival were considered as an expression of aggressive infection by an isolate. The majority of the isolates caused severe systemic necrosis, stunting, and in some cases, death of plants. TSWV infection is known to result in diverse symptomatology in field grown tobacco (30; Fig. 1), which is possibly due to the existence of different isolates. Symptom expression is also affected by time of infection, age of the plant, and environmental factors. We isolated and characterized two biologically distinct isolates that differed in virulence as shown by the differential response of selected cultivars of peanut, tomato, and tobacco. Tobacco cultivar K326 is one of the predominant tobacco cultivars grown in Georgia. Although GATb-1 and GAL isolates both infected K326, only GAL was destructive to it. In peanut, cultivars Georgia Runner and Georgia Green, which are susceptible and moderately field resistant to TSWV, respectively, showed similar disease responses to both isolates. Peanut breeding line C11-2-39, however, showed suppression of the mild isolate, GATb-1, but not the severe isolate, GAL, as shown by the percent infected plants. In previous studies with natural (12) and mechanical inoculation (22), C11-2-39 was found to be a promising source of resistance to TSWV, but the present study showed that the severe isolate occurring in Georgia can overcome resistance in this breeding line. It is not known how C11-2-39 would respond to GAL in a field environment. However, existence of such an aggressive isolate in Georgia necessitates continued search for different and better sources of TSWV resistance in peanut.

Tomato cultivar BHN 444 suppressed the systemic symptoms caused by the severe isolate GAL and both local and systemic symptoms of the mild isolate GATb1 as determined by visual observation and ELISA. BHN 444 is a newly released TSWV-resistant cultivar. Our results indicate that BHN 444 has a high level of resistance against both GATb-1 and GAL isolates.

TSWV resistance was reported in two accessions of Capsicum chinense, PI 152225 and PI 159236, against seven Louisiana TSWV isolates $(6,17)$, and localization of TSWV in resistant and susceptible Capsicum accessions was reported (40). Boiteux and Nagata (7) reported breakdown of resistance in PI 159236 against three TSWV isolates from Brazil. The pepper cultivar Stiletto was released for commercial use by Novartis/Rogers Brand Seed as a TSWV-resistant cultivar after extensive field trials. In the present study,

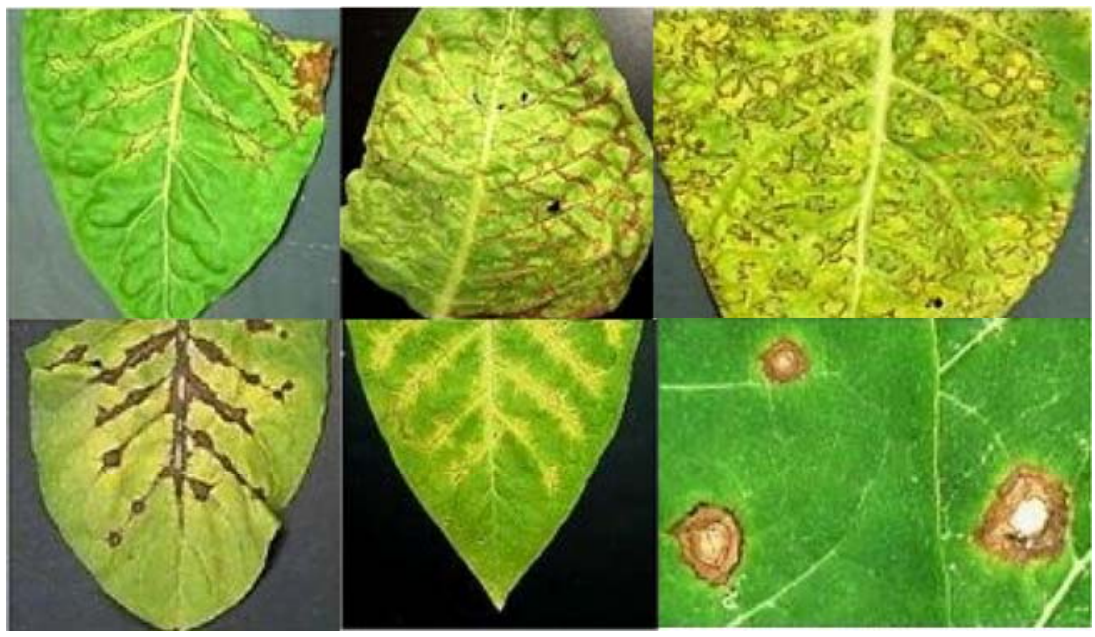

Fig. 1. Variation of symptoms of Tomato spotted wilt virus on field-grown tobacco.
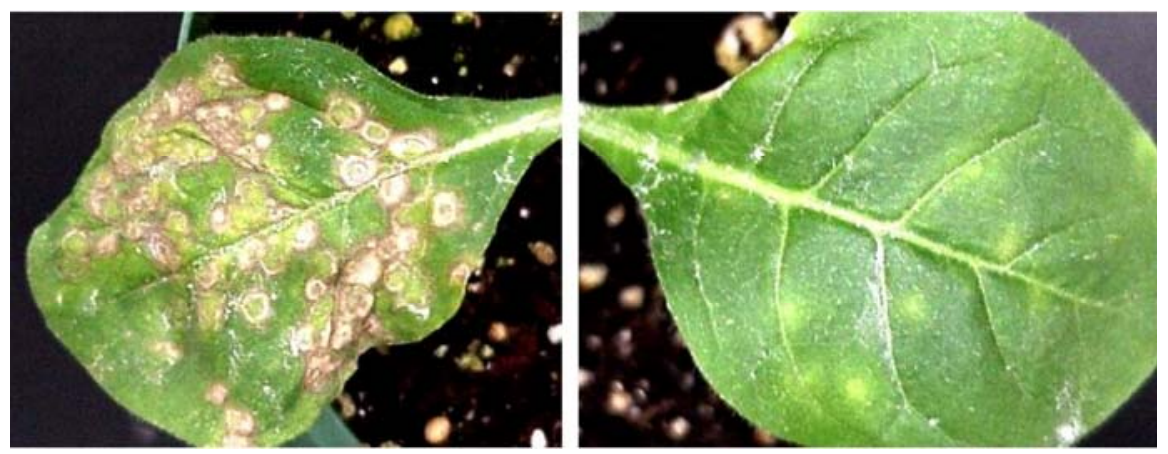

Fig. 2. Symptoms caused by Tomato spotted wilt virus isolates on tobacco cv. K326. Left, necrotic lesions and systemic necrosis caused by GAL isolate; right, chlorotic spots caused by GATb- 1 isolate. 
mechanical inoculation of 1-month-old seedlings showed a high percentage of infection ( 81.2 to $93.8 \%$ ) by GATb-1 and GAL isolates. Infection by GAL was more destructive than that caused by GATb-1, because necrosis caused by the GAL isolate resulted in defoliation of all the leaves and arrested further growth of the plants.

The differential response of several cultivars of peanut and tomato to two isolates of TSWV confirmed that the biological differences between these isolates are consistent. We also showed that an isolate that has mild effects on one crop can be severe on another crop. For example, isolate GATb-1 was mild in tobacco and tomato, but it was severe in pepper and peanut. The relative prevalence of strains differing in virulence could be a contributing factor to varying levels of disease incidence observed over the years. Availability of biologically distinct isolates such as GATb-1 and GAL may facilitate a better understanding of the genetic determinants for symptomatology and severity. Using such symptom variants, Qiu and Moyer $(34,35)$ demonstrated the genome reassortment between two TSWV isolates. TSWV variants that differed in thrips transmission were used to demonstrate the role of glycoproteins in TSWV-thrips association (39).

Due to the wide occurrence of thrips vectors and possible alternate sources of inoculum, control of TSWV is difficult. However, integration of multiple tactics has been shown to be effective in managing TSWV in peanut, tobacco, and tomato $(8,10,11,13,14,23,32,36,37)$. Of all the control tactics, use of a resistant cultivar is the most effective means for the management of TSWV. Infection of the newly introduced TSWV-resistant cultivars such as BHN 444 and Stiletto by the TSWV isolates indicates that TSWV strains that differ in virulence continue to pose a threat. Data presented here on the differential response of commercially grown cultivars of economically important crops highlight the need to use multilocation trials and as many strains as possible in screening of germ plasm and breeding lines for TSWV resistance.

\section{ACKNOWLEDGMENTS}

We are thankful to Wanda Tillery for technical help. This work was supported in part by funding from Georgia Agricultural Commodity Commission for Peanut, Georgia Agricultural Commodity Commission for Tobacco, and USDA-CSREES Special Grant (99-34412-7415). B. Mandal was supported by a postdoctoral fellowship from the USDA-CSREES Special Grant (99-34412-7415). Supported by the Washington State UniversityCollege of Agricultural, Human and Natural Resource Sciences (Project 0545). The paper is listed as Plant Pathology New Series 0414.

\section{LITERATURE CITED}

1. Adkins, S. 2000. Tomato spotted wilt virusPositive steps towards negative success. Mol. Plant Pathol. 3:151-157.

2. Bandla, M. D., Westcot, D. M., Chenault, K.
D., Ullman, D. E., German, T. L., and Sherwood, J. L. 1994. Use of monoclonal antibody to the nonstructural protein encoded by the small RNA of tomato spotted wilt tospovirus to identify viruliferous thrips. Phytopathology 84:1427-1431.

3. Best, R. J. 1968. Tomato spotted wilt virus. Pages 65-145 in: Advances in Virus Research. K. M. Smith and M. A. Lauffer, eds. Academic Press, New York.

4. Best, R. J., and Gallus, H. P. C. 1953. Strains of tomato spotted wilt virus. Aust. J. Sci. 15:212-214.

5. Bhat, A. I., Pappu, S. S., Pappu, H. R., Deom, C. M., and Culbreath, A. K. 1999. Analysis of the intergenic region of tomato spotted wilt virus medium RNA segment. Virus Res. 61:161170.

6. Black, L. L., Hobbs, H. A., and Gatti, J. M., Jr. 1991. Tomato spotted wilt virus resistance in Capsicum chinense PI 152225 and 159236. Plant Dis. 75:863.

7. Boiteux, L. S., and Nagata, T. 1993. Susceptibility of Capsicum chinense PI 159236 to tomato spotted wilt virus isolates in Brazil. Plant Dis. 77:210.

8. Brown, S., Todd, J., Culbreath, A., Baldwin, J., Beasley, J., and Pappu, H. 2000. Tomato spotted wilt of peanut: Identifying and avoiding high-risk situations. Univ. Georgia Coop. Ext. Serv. Bull. 1165.

9. Chatzivassiliou, E. K., Weekes, R., Morris, J., Wood, R. K., Barker, I., and Katis, N. I. 2000. Tomato spotted wilt virus (TSWV) in Greece: Its incidence following the expansion of Frankliniella occidentalis, and characterisation of isolates collected from various hosts. Ann. Appl. Biol. 137:127-134.

10. Cho, J. J., Custer, D. M., Brommonschenkel, S. H., and Tanksley, S. D. 1996. Conventional breeding: Host-plant resistance and the use of molecular markers to develop resistance to tomato spotted wilt virus. Acta Hortic. 431:367378.

11. Csinos, A. S., Pappu, H. R., McPherson, R. M., and Stephenson, M. G. 2001. Management of Tomato spotted wilt tospovirus in flue-cured tobacco with acibenzolar- $S$-methyl and imidacloprid. Plant Dis. 85:292-296.

12. Culbreath, A. K., Todd, J. W., and Brown, S. L. 2003. Epidemiology and management of tomato spotted wilt in peanut. Annu. Rev. Phytopathol. 41:53-75.

13. Culbreath, A. K., Todd, J. W., Brown, S. L., Baldwin, J. A., and Pappu, H. R. 1999. A genetic and cultural package for management of tomato spotted wilt virus in peanut. Biol. Cult. Tests 14:1-8.

14. Culbreath, A. K., Todd, J. W., Gorbet, D. W., Brown, S. L., Baldwin, J. A., Pappu, H. R., Holbrook, C. C., and Shokes, F. M. 1999. Response of early, medium, and late maturing peanut breeding lines to field epidemics of tomato spotted wilt. Peanut Sci. 26:100-106.

15. de Avila, A. C., Huguenot, C., Resende, R. D. O., Kitajima, E. W., Goldbach, R. W., and Peters, D. 1990. Serological differentiation of 20 isolates of tomato spotted wilt virus. J. Gen. Virol. 71:2801-2807.

16. Elliot, R. M. 1996. The Bunyaviridae: Concluding remarks and future prospects. Pages 295-332 in: The Bunyaviridae. R. M. Elliot, ed. Plenum Press, New York.

17. Hobbs, H. A., Black, L. L., Johnson, R. R., and Valverde, R. A. 1994. Difference in reactions among tomato spotted wilt virus isolates to three resistant Capsicum chinense lines. Plant Dis. 78:1220

18. Hoffmann, K., Qiu, W. P., and Moyer, J. W. 2001. Overcoming host- and pathogenmediated resistance in tomato and tobacco maps to the M RNA of tomato spotted wilt virus. Mol. Plant-Microbe Interact. 14:242-249.

19. Jain, R. K., Pappu, S. S., Pappu, H. R., Cul- breath, A. K., and Todd, J. W. 1998. Molecular diagnosis of tomato spotted wilt tospovirus in fection of peanut and other field and greenhouse crops. Plant Dis. 82:900-904.

20. Latham, L. J., and Jones, R. A. C. 1998. Selection of resistance breaking strains of tomato spotted wilt tospovirus. Ann. Appl. Biol 133:385-402.

21. Mandal, B., Pappu, H. R., and Culbreath, A. K. 2001. Factors affecting mechanical transmission of Tomato spotted wilt virus to peanu (Arachis hypogaea). Plant Dis. 85:1259-1263.

22. Mandal, B., Pappu, H. R., Culbreath, A. K., Holbrook, C. C., Gorbet, D. W., and Todd, J. W. 2002. Differential response of selected peanut (Arachis hypogaea) genotypes to mechanical inoculation by Tomato spotted wilt virus. Plant Dis. 86:939-944.

23. Momol, M. T., Olson, S. M., Funderburk, J. E., Stavisky, J., and Marois, J. J. 2004. Integrated management of tomato spotted wilt on fieldgrown tomatoes. Plant Dis. 88:882-890.

24. Moury, B., Palloix, A., Selassie, K. G., and Marchoux, G. 1997. Hypersensitive resistance to tomato spotted wilt virus in three Capsicum chinense accessions is controlled by single gene and overcome by virulent strains. Euphytica 94:45-52.

25. Moyer, J. W. 1999. Tospoviruses (Bunyaviridae). Pages 1803-1807 in: Encyclopedia of Virology. A. Granoff and R. G. Webster, eds. Academic Press, San Diego, CA.

26. Moyer J. W. 2000. Tospoviruses. Pages 592597 in: Encyclopedia of Microbiology. R. Hull, ed. Academic Press, London.

27. Moyer, J. W., Tsompana, M., Sin, S. H., and Abad, J. A. 2003. Evolutionary biology of tomato spotted wilt virus. (Abstr.) Phytopathology 93:S99.

28. Norris, D. O. 1946. The strain complex and symptoms development of spotted wilt virus. Aust. C.S.I.R.O. Bull. No. 202.

29. Padgett, G. B., Bertrand, P. F., and Gay, J. D. 1995. Spotted wilt in Georgia's crops. Univ. Georgia Coop. Ext. Serv. Bull. 1127.

30. Pappu, H. R. 1999. Tomato spotted wilt virus on tobacco. Image of the Week. American Phytopathological Society. Online. Publication no. IW00004.

31. Pappu, S. S., Bhat, A. I., Pappu, H. R., Deom, C. M., and Culbreath, A. K. 2000. Phylogenetic studies of tospoviruses (Family: Bunyaviridae) based on intergenic region sequences of small and medium genomic RNAs Arch. Virol. 145:1035-1045.

32. Pappu, H. R., Csinos, A. S., McPherson, R. M., Jones, D. C., and Stephenson, M. G. 2000. Effect of acibenzolar-S-methyl and imidacloprid on suppression of tomato spotted wilt tospovirus in flue-cured tobacco. Crop Prot. 19:349-354.

33. Pappu, H., Pappu, S., Jain, R., Bertrand, P., Culbreath, A. K., Mcpherson, R., and Csinos, A. 1998. Sequence characteristics of natural populations of tomato spotted wilt Tospovirus infecting flue-cured tobacco in Georgia. Virus Genes 17:169-177.

34. Qiu, W. P., Geske, S. M., Hickey, C. M., and Moyer, J. W. 1998. Tomato spotted wilt Tospovirus genome reassortment and genomespecific adaptation. Virology 244:186-194.

35. Qiu, W., and Moyer, J. W. 1999. Tomato spotted wilt tospovirus adapts to the TSWV N gene-derived resistance by genome reassortment. Phytopathology 89:575-582.

36. Riley, D. G., and Pappu, H. R. 2000. Evaluation of tactics for management of thripsvectored Tomato spotted wilt virus in tomato. Plant Dis. 84:847-852.

37. Riley, D. G., and Pappu, H. R. 2004. Tactics for Management of Thrips (Thysanoptera: Thripidae) and Tomato Spotted Wilt Virus in Tomato. J. Econ. Entomol. 97:1648-1658.

38. Sherwood, J. L., German, T. L., Moyer, J. W., 
Ullman, D. E., and Whitfield, A. E. 2000. Tomato spotted wilt. Pages 1030-1031 in: Encyclopedia of Plant Pathology. O. C. Maloy and T. D. Murray, eds. John Wiley \& Sons, New York.

39. Sin, S.-H., McNulty, B. C., Kennedy, G. G., and Moyer, J. W. 2005. Viral genetic determinants for thrips transmission of Tomato spotted wilt virus. Proc. Natl. Acad. Sci., USA 102:5168-5173.
40. Soler, S., Diez, M. J., Rosello, S., and Nuez, F. 1999. Movement and distribution of tomato spotted wilt virus in resistant and susceptible accessions of Capsicum spp. Can. J. Plant Pathol. 21:317-325.

41. Tsompana, M., Abad, J., Purugganan, M., and Moyer, J. W. 2005. The molecular population genetics of the Tomato spotted wilt virus (TSWV) genome. Mol. Ecol. 14:53-66.

42. Ullman, D. E., Meideros, R., Campbell, L. R.,
Whitfield, A. E., Sherwood, J. L., and German, T. L. 2002. Thrips as vectors of tospoviruses. Adv. Bot. Res. 36:113-140.

43. Whitfield, A. E., Ullman, D. E., and German, T. L. 2005. Tospovirus-thrips interactions Annu. Rev. Phytopathol. 43:459-489.

44. Williams-Woodward, J. L. 2000. 1999 Georgia plant disease loss estimates. Univ. Georgia Crop Ext. Serv. Publ. Path 99-002. June 1999. 